\title{
Helping Yourself or Others? Motivation Dynamics for High- Performing Volunteers in GLAM Crowdsourcing
}

\author{
Sultana Lubna Alam \\ Deakin Business School \\ Deakin University \\ Australia \\ lubna.alam@deakin.edu.au
}

\section{Ruonan Sun}

Research School of Management

Australian National University

\section{John Campbell}

Australian National University

\section{Abstract}

While most crowdsourcing (CS) cases in the literature focus on commercial organisations, little is known about volunteers' motivation of initial and continued participation in not-for-profit CS projects and importantly, about how the motivations may change over time. It is vital to understand motivation and motivational dynamics in a not-for-profit context because a fundamental challenge for not-for-profit CS initiations is to recruit and keep volunteers motivated without any formal contract or financial incentives. To tackle this challenge, we explore high performing volunteers' initial motivation for joining and sustaining with a GLAM (galleries, libraries, archives and museums) CS project. We situated our interpretive exploration in a case study of the Australian Newspapers CS project initiated by the National Library of Australia. Based on the case study, we found that high-performing volunteers were motivated by a combination of personal, collective, and external factors classified into intrinsic, extrinsic, and internalised extrinsic motivations. Further, we found that these motivations changed over time. Specifically, many volunteers presented substantial personal (i.e., personal interest and fun) and community-centric motivations (i.e. altruism and non-profit cause) when they initially joined the project, whereas external motivations (i.e., recognition and rewards) had a greater impact on long-term participation. Our findings offer implications for CS system design (e.g., user profiles, tagging and commenting), incentive structure (e.g., reputationbased ranking, leader boards), and relational mechanisms (e.g., open communication channels) to stimulate sustainable contributions for not-for-profit CS initiatives.

Keywords: Motivation, Crowdsourcing, Not-for-profit, Motivation dynamics, GLAM

\section{Introduction}

Crowdsourcing (CS) refers to the act of harnessing diverse potential of external contributors by issuing open calls for accomplishing particular tasks via online platforms (Adams and Ramos 2010; Howe 2006). Gartner predicted that 75 per cent of high-performing enterprises would use CS in some forms by 2018 (Grewal-Carr et al. 2016). Not-for-profit organizations, such as government agencies and GLAM (galleries, libraries, archives, and museums), increasingly employ CS to better leverage collective knowledge and experience of external crowd to establish connections, understand requirements, and coordinate actions. This paper focuses on not-for-profit CS because its fundamental challenge is to recruit and keep 
volunteers motivated to contribute without any monetary incentives (Alam and Campbell 2017). Furthermore, not-for-profit organizations do not have a reasonably agreed upon goal of profit maximization and, thereby making success measurement more challenging (Chandler 1962).

Although CS has drawn increasing attention from the literature, most studies focused on CS activities initiated by commercial organisations (Afuah and Tucci 2012; Brabham 2010; Grewal-Carr and Bates 2016; Kaufmann et al. 2011; Rodell 2013; Schlagwein and BjørnAndersen 2014). Not-for-profit CS initiations are scant in the IS literature. The growing CS use by not-for-profit organisations is facilitating new forms of digital volunteerism where no formal contract or monetary compensation are provided (Benkler and Nissenbaum 2006; Cobb et al. 2014; Dutton 2010; Starbird and Palen 2011). CS for social goals (e.g., supporting public libraries and people with disabilities) has recently received increasing attention from scholars (Alam and Campbell 2017; Kobayashi et al. 2015). In particular, CS use by GLAM is boosted by the emergence of digital workers and the rising importance of information and cultural production (Oomen and Aroyo 2011; Owens 2013; Ridge 2013). In a not-for-profit context, CS can help extend and redefine the long-standing traditions of volunteerism, such as citizen involvement in the creation and enhancement of public and cultural goods (Holley 2010; Karen and Cyndi 2011; Oomen and Aroyo 2011). The tasks carried out by CS volunteers typically include correction, contextualization, collection, classification, co-curation, and crowdfunding (Oomen and Aroyo 2011).

The literature has identified volunteers' motivation as a critical factor for CS success. However, limited research considered motivation dynamics in CS settings (Crowston and Fagnot 2018; Taylor and Joshi 2019), especially in a not-for-profit GLAM context. GLAM CS initiative is different in terms of ownership, task autonomy, and the types of tasks outsourced. Specifically, volunteers contribute towards a common cultural goal where the data, knowledge, or other products created by volunteers are overseen and managed by a GLAM institution, as the custodian or caretaker of these new cultural assets. Many GLAM institutions found it difficult to attract and retain volunteers on their CS platforms. Our study seeks to address this issue by exploring volunteers' motivations of a successful library CS with the aim of gaining an understanding of the motivation dynamics from initial to continued participation. While contextual factors have a significant bearing on the efficacy of different motivators in CS projects, there remains the need for a more rigorous theoretical orientation to understand CS phenomena in the GLAM sector. In so doing, we also respond to the call for information systems researchers to extend their focus to non-traditional commercial organisations (Majchrzak and Malhotra 2013).

We investigate why and how high-performing volunteers joined and continued to participate in a large-scale, not-for-profit GLAM CS project, the Australian Newspaper Digitization Program (ANDP), initiated by the National Library of Australia (NLA)); now known as Trove (https://trove.nla.gov.au/). We employed the notions of intrinsic and extrinsic motivations to gain insights into (1) volunteers' motivation for joining the ANDP Trove, (2) their ongoing motivations to continue contributing to ANDP, and (3) work practices and strategies for transitioning novice volunteers into leading high-performance contributors over time. Greater understanding of these motivations and their temporal aspects will lead to better CS designs to facilitate broader and sustained collaboration between GLAM and volunteers. 
The rest of the paper proceeds as follows. We first survey the state of knowledge about volunteer motivation to identify gaps in motivation research. Next, we report on our case study research method followed by a comprehensive case analysis. Based on the case analysis, we present a typology of the motivation dynamics, leading to a discussion on the importance of understanding the temporal aspects in volunteer motivation in not-for-profit CS initiations. We conclude with implications, limitations, and opportunities for future research.

\section{Conceptual Background}

\subsection{CS Volunteer Motivation}

The extant research has built on the dichotomy of intrinsic and extrinsic motivations based on the self-determination theory (SDT) to examine motivational dynamics in CS settings (Deci et al. 1989; Ryan and Deci 1985; 2000). The SDT focuses on human intensions from which inferences could be drawn about whether specific events tend to be autonomous or controlled (Deci et al. 1989, p. 580). Autonomy means 'endorsing one's action at the highest level of reflection' (Gagné and Deci 2005, p. 334). Intrinsic motivation exemplifies autonomy and emphasises inherent sources of satisfaction (e.g., acting just for fun) when people engage an activity (Ryan and Deci 2000). On the contrary, control involves 'acting with a sense of pressure, a sense of having to engage in the action' (Gagné and Deci 2005, p. 334). For example, extrinsic motivation (e.g., acting for money) has been experimented as an instrument for achieving a certain desired outcome.(Ryan and Deci 2000).

In their systematic review of open source software development literature ${ }^{1}$, Von Krogh and colleagues (2012) identified three classes of motivations based on the SDT: (1) intrinsic motivations such as ideology, altruism, kinship, and fun, (2) extrinsic motivations such as career and pay, and (3) internalised extrinsic motivations that have extrinsic qualities but are internalised in ways that become self-regulating. Hemetsberger (2004) viewed motivation as 'self-interest' and 'others-orientation' (as cited in (von Krogh et al. 2012). Self-interest was further segmented into task and product-related motivation (corresponding to intrinsic motivation); others-orientation, including long-term utilitarian goals and social significance (corresponding to extrinsic motivation) was separated into internalised group goals and values, and socio-emotional relationships. Kobayashi et al. (2015) added similar dimensions of personal vs. social aspects to intrinsic and extrinsic motivations by studying a system that supported people with disabilities. Table 1 summarises relevant literature delineating motivations for participating in CS projects and uses Kobayashi et al.'s personal and social categories to demarcate internally and externally sourced motivation. Most CS projects in Table 1 were in the not-for-profit context (e.g. Wikipedia, open source community, user generated content, online community, crowdfunding). Only Kaufmann et al. (2011) (Amazon Mechanical Turk) and Brabham (2010) (Threadless) examined contexts where monetary incentives were provided.

\footnotetext{
${ }^{1}$ We argue that motivations of open source software development can indicate insights into motivations of mot-for-profit CS initiations because extensive research on motivating crowds to contribute to CS initiatives has been in the context of open source software development (Afuah and Tucci 2012).
} 


\begin{tabular}{|c|c|c|c|}
\hline $\begin{array}{c}\text { Motivation } \\
\text { Category }\end{array}$ & Sub-Category & Term from paper(s) & Papers \\
\hline \multirow[t]{2}{*}{$\begin{array}{l}\text { Intrinsic- } \\
\text { Personal }\end{array}$} & Affective & $\begin{array}{l}\text { Fun, Enjoyment, Curiosity, } \\
\text { Task autonomy, Task } \\
\text { identity, Learning, Own- } \\
\text { use, Pastime, Rituals and } \\
\text { habit, }\end{array}$ & $\begin{array}{l}\text { Crowston and Fagnot 2018, Ye and } \\
\text { Kankanhalli 2017, McInnis et al. (2016), } \\
\text { Kobayashi et al. (2015), Von Krogh et al. } \\
\text { (2012), Nov (2007), Brabham (2010), Rafaeli } \\
\text { and Ariel (2008) }\end{array}$ \\
\hline & $\begin{array}{l}\text { Personally } \\
\text { (self-oriented) } \\
\text { motivation }\end{array}$ & $\begin{array}{l}\text { Interest, Personal } \\
\text { growth/self-fulfilment, } \\
\text { Personal taste/preference }\end{array}$ & $\begin{array}{l}\text { Crowston and Fagnot 2018, Rafaeli and } \\
\text { Ariel (2008), Kaufmann et al. (2011), } \\
\text { Kobayashi et al. (2015) }\end{array}$ \\
\hline $\begin{array}{l}\text { Intrinsic- } \\
\text { Social }\end{array}$ & $\begin{array}{l}\text { Community- } \\
\text { based }\end{array}$ & $\begin{array}{l}\text { Altruism, Kinship, External } \\
\text { self-concept (meets } \\
\text { expectations of group), } \\
\text { Reciprocity, Ideology }\end{array}$ & $\begin{array}{l}\text { Crowston and Fagnot 2018, McInnis et al., } \\
2016 \text {, Kobayashi et al. (2015), Gerber and } \\
\text { Hui (2013), Von Krogh et al. (2012), Malone } \\
\text { et al. (2010), Rafaeli and Ariel (2008), Yang } \\
\text { and Lai (2010) }\end{array}$ \\
\hline \multirow[t]{3}{*}{$\begin{array}{l}\text { Extrinsic- } \\
\text { Personal }\end{array}$} & $\begin{array}{l}\text { Human capital } \\
\text { advancement }\end{array}$ & $\begin{array}{l}\text { Internal self-concept, } \\
\text { Human capital } \\
\text { advancement, Signalling, } \\
\text { Career, learning }\end{array}$ & $\begin{array}{l}\text { Deng et al. (2016, Yang and Lai (2010), } \\
\text { Gerber and Hui (2013), Von Krogh et al. } \\
\text { (2012), Brabham (2012), Rafaeli and Ariel } \\
\text { (2008 }\end{array}$ \\
\hline & Payment & Pay (monetary) & $\begin{array}{l}\text { Deng et al 2016, Kaufmann et al 2011, } \\
\text { Gerber and Hui (2013) }\end{array}$ \\
\hline & Reward & $\begin{array}{l}\text { Recognition, Reputation, } \\
\text { Self-expression }\end{array}$ & $\begin{array}{l}\text { Crowston and Fagnot (2018), Deng et al } \\
\text { (2016), Kobayashi et al. (2015), Von Krogh } \\
\text { et al. (2012), Malone et al. (2010), Brabham } \\
\text { (2012) }\end{array}$ \\
\hline \multirow[t]{2}{*}{$\begin{array}{l}\text { Extrinsic- } \\
\text { Social }\end{array}$} & \multirow[t]{2}{*}{ Social Contact } & $\begin{array}{l}\text { Indirect feedback, } \\
\text { Diversion, Social integration }\end{array}$ & $\begin{array}{l}\text { Crowston and Fagnot (2018), Kobayashi et } \\
\text { al. (2015), Rotman et al. (2012), Kaufmann et } \\
\text { al. (2011), Malone et al. (2010) }\end{array}$ \\
\hline & & $\begin{array}{l}\text { Chance to socialize, Chance } \\
\text { for collaboration, Advocacy }\end{array}$ & $\begin{array}{l}\text { Crowston and Fagnot (2018), Kobayashi et } \\
\text { al. (2015), Rotman et al (2012), Malone et al. } \\
\text { (2010), Brabham (2012) }\end{array}$ \\
\hline
\end{tabular}

Table 1. Summary of the Literature on Motivation for Participating in CS Projects

The intrinsic-personal motivation including fun and enjoyment are frequently found positively related to CS participation (Crowston and Fagnot 2018; von Krogh et al. 2012; Nov et al. 2007; Malone et al. 2010; Brabham 2012; Rafaeli and Ariel 2008; Ye and Kankanhalli 2017). For example, Nov et al. (2007) and Rafaeli and Ariel (2008) examined motivations of contributors to Wikipedia and identified that fun was one of the top motivators for participation. Similarly, Crowston and Fagnot (2018) found curiosity and fun as major motivators for user-generated content contributors Further, even in a commercial context, Kaufmann et al. (2011) developed a comprehensive model of worker's motivations for paid CS initiatives (e.g. Amazon Mechanical Turk) and found that 'task autonomy' was one of the two most prominent factors for motivation.

In terms of intrinsic-social motivation, Gerber and Hui (2013), van Krogh et al. (2012), and Rafeli and Ariel (2008) identified altruism. Geiger and Hui (2013) studied motivations and deterrents for creators and supporters to participate in crowdfunding projects. Yang and Lai (2010) identified external self-concept motivation in their study of Wikipedia contributors that fits well with the category of intrinsic-social motivation. External self-concept motivation is the primary motivation for individuals to adopt an activity that is congruent with the expectations of a reference group. Crowston and Fagnot (2018) found social motives important for user- 
generated content. Von Krogh et al. (2012) also found reciprocity as an important motivator for non-profit contexts.

Kobayashi et al. (2015) classified motivations in extrinsic-personal category as human capital advancement, signalling, payment, and reward. Human capital advancement is related to the notion of internal self-concept (Yang \& Lai, 2010). Internal self-concept motivation refers to the force that drives individuals to pursue an activity that meets their inherent standards. Yang and Lai (2010) found that internal self-concept was strongly correlated with knowledgesharing behaviour through an online survey. Human capital advancement is also equivalent with learning (Brabham, 2012; Gerber and Hui 2013; Rafaeli \& Ariel 2008; van Krogh et al., 2012) as well as own use for personal purposes (von Krogh et al., 2012). Others are motivated by signalling (Kobayashi et al., 2015), such as reputation (Gerber and Hui 2013; von Krogh et al., 2012; Malone et al., 2010; Rafaeli \& Ariel 2008) and self-expression (Brabham 2012). Brabham (2012) synthesized Ryan and Deci's (2000) model with Knoke and Wright-Isak's (1982) classifications to examine a transit-planning project. The only reward offered to the winners of that competition was acknowledgement in a press release and a formal announcement on the competition web site. Brabham (2012) found that a mixture of intrinsic and extrinsic motivators including the opportunity for career advancement, motivated CS participation behaviour. This finding is also consistent with the findings by Geiger and Hui (2013) in their study of crowdfunding. Further, extrinsic-personal motivations are enabled by more traditional incentives (Whyte 1955), such as payment and reward (Deng et al 2016; Geber and Hui 2013; Kaufmann et al., 2011; Rafaeli \& Ariel 2008; von Krogh et al. (2012).For example, - glory or recognition is at hand if volunteers are motivated by the desire to be recognised by peers for their contributions (Malone et al. 2010).

The final category, extrinsic-social motivations include social integration (Rafaeli and Ariel 2008), chance to socialize (Malone et al. 2010), chance for collaboration (Brabham 2012), indirect feedback (Rotman et al. 2012; Kaufmann et al. 2011), and advocacy (Rotman et al. 2012).

\subsection{Motivation Dynamics}

In this paper, we define motivation dynamics as changes in motivation over time; specifically from initial participation to continued participation. Although the literature has shown rich insights into motivation of participating in CS projects, we recognize that few studies considered motivation dynamics. In psychology, researchers have found that people's motivation of doing something is often different and changes over time (Turner and Patrick 2008). CS projects are inherently complex activities that spread over long periods and span multiple tasks. In these projects, motivations may not only change over time, but could also be particularly salient at critical junctions of activity and decision making (Rotman et al. 2014; Rotman et al. 2012; Turner and Patrick 2008). However, in prior research, motivation for contribution has been considered 'a single, static and individual phenomenon' (Crowston and Fagnot 2018, p.89).

In a recent study on Wikimedia Editor Survey, Crowston and Fagnot (2018) found that different stages of contribution have distinct motives. Using the theory of helping behaviour as a framework and integrating social movement theory, they proposed a stage theory that distinguishes separate motivations for initial, sustained, and meta contributions for participation in user-generated content. They found initial contributions were motivated largely by curiosity; sustained contributions largely by intrinsic interest; and meta- 
contributions increasingly by social motives. Rotman et al. $(2012,2014)$ studied the dynamic aspects of motivation in collaborative citizen science projects and found that the temporality affected three decision points in time: (1) volunteers' initial decision to participate in a project, (2) active participation, and (3) the ensuing decision to continue once the initial task was completed. They found that both scientists and volunteers presented egoism as the primary motivation for initial engagement. However, beyond initial engagement, altruism, and collectivism played important roles in the decision to continue participation. This scant research confirms our proposition that it is a mistake to assume that the motives for sustained volunteers are just more of whatever got them to initially participate. Thus, motivation dynamics have potentially important theoretical and design implications that this study will explore.

In sum, the literature on CS motivation has not reflected a cumulative body of systematic work on the changing nature of motivational dynamics over time. This indicates a need for further work on theorising the temporal aspects with a rich in-depth exploration, in particular without any formal contract and financial incentive. Responding to this gap in literature, this study addresses the research question: How does motivation changes from initial participation to continued participation in a not-for-profit setting? Answering this question is important because they are relevant to tackling some of CS's fundamental challenges, such as how to recruit and keep volunteers motivated to continue participation (Doan et al. 2011).

The current paper builds on existing work of the authors for non-profit CS for GLAM sector. In Alam and Campbell (2016), the authors studied temporal aspects of organisational motivation to CS. In Alam and Campbell (2017), the focus was on changes in participant motivation across different types of contributions. They proposed that there were two forms of contribution: data shaping and knowledge shaping. They theorised how the focus and locus of motivation changes across these two types of contributions at crowd and community level over time. Continuing the work on the role of temporality in participant motivation for notfor-profit GLAM CS (e.g. Alam and Campbell 2012), in this current paper, we focus on how motivation changes from initial participation to continued participation based on the intrinsic and extrinsic dichotomy. We examine how motivation to CS participation changes over time by examining the participation journeys of high performing volunteers in a case study.

\section{Research Method}

We adopted an interpretive research approach to explore CS motivation dynamics with a unique CS case. An interpretive approach is suitable because it is particularly strong in uncovering novel insights for accessing intricate details, thought processes and emotions (Klein and Myers 1999; Orlikowski and Baroudi 1991). The ANDP and the Trove is an appropriate site for this study for three reasons. First, the ANDP is a large-scale GLAM CS initiative and as such publicly available data ensures the richness of our data sources. Notably the NLA is the third largest library in the world. Second, Trove was launched in 2008, which provided us longitudinal, first-hand observations of participants' contributions and motivations. Third, since ANDP (i.e. Trove) is an on-going project, it allows us to explore motivation dynamics on a temporal base.

\subsection{The ANDP Case}

We explore the motivations of high performing correctors in the ANDP. The ANDP aimed to provide an online full-text searchable digitised newspaper delivery system of out of copyright 
Australian newspapers from 1803 to 1954 (https://trove.nla.gov.au/). However, numerous errors were recorded during the optical character recognition (OCR) process that greatly limited the searchability of entries. Unfortunately, the NLA did not have the resources to rectify the errors thus CS was a potential cost-effective solution. To address such issue, the ANDP released the Trove platform, which provides a split screen view of the scanned image of the newspaper and the OCR transcription. The design of the page is suited for corrections, as the original document is immediately juxtaposed with the transcription, so errors are more apparent. Corrections can also be made in the form of comments linked to an article, giving users an opportunity to record their own narrative or interpretation of historical events. Users can view the history of corrections, including both the corrected and the original OCR text. Text corrections are saved to a database and are subsequently added to the search results. However, corrected text does not overwrite the original text contained in the article. Both the corrected text and the original text are indexed and searchable.

As at September 2019, 294,889 registered volunteers have corrected and enhanced more than 325 million lines, added seven million tags, left 248,212 comments, and created 36,287 merges/splits on Trove. On an average, 8,000 registered volunteers actively contribute to the correction each month. Trove users who corrected text were more likely to be family historians, retired, and long-term (more than one year) frequent Trove users (Ayres 2013). Sixty-five percent of users are aged 50 or over; 34 per cent are aged 60 or over; only 17 per cent of users were aged under 40 (Ayres 2013). Similar to other commons-based peer production systems like Wikipedia, Hagon (2013)'s research on Trove user engagement found that the top 100 users have undertaken 43 percent of all corrections (i.e., 41 million lines of text), and the top 1,000 users have undertaken $81 \%$ of the corrections. Hence, we examined the motivations of the high performing text correctors and were in the aged 50 or over

\subsection{Data Collection and Analysis}

Overall, 20 in-depth interviews were carried out over 2012-2013, which included six leading text correctors and two representatives of group text correctors (see Table 2, note Mr and Mrs Hoy corrected using the same Trove account). Interviews lasted between one to two hours and were undertaken by telephone or Skype. Volunteers were selected using purposeful sampling and snowball approach (Patton 2000). As we focused on high-performing volunteers, a majority (five out of six) of the interviewees were listed as the top 10 text correctors in the Trove Hall of Fame. They were approached through the Trove forum platform, sending invitations by personal messages using their user profile. The interviews were both semistructured and relatively informal. They usually centred on involvement with the Australian Newspapers site - motivations for participating, text correction practices, perspectives and sentiments towards CS, risks and concerns, support received, and CS platform. The interviewees to illustrate their perspectives and experiences often shared anecdotes and specific narratives. Data collection ended at the point of redundancy (Lincoln and Guba 1985)'when efforts to get additional members cannot be justified in terms of the additional outlay of energy and resources' (p.233).

The secondary interviews (twelve) and Trove user profiles were used to triangulate the text corrector's recount of their journey. To achieve triangulation, we collected data from three sources of evidence: ANDP documentation, Trove observation, and interviews (Eisenhardt 1989). We analysed ANDP press releases, NLA reports, Trove user surveys and extant literature on the case study (e.g. in particular publications by Holley 2009, 2010 who was the 
project manager of ANDP). Further, first author registered as a Trove user to observe how the CS platform was used to gain representative experience. All interviews were recorded and transcribed. NVivo was used for textual content analysis. We used data gathered from documentation and Trove operation to corroborate, validate, and complement interview data.

\begin{tabular}{|c|c|c|c|}
\hline Number & Age & Status & Brief Narrative of their journey \\
\hline 1 & $60-70$ & $\begin{array}{l}\text { Retired. } \\
\text { Principal } \\
\text { technical officer }\end{array}$ & $\begin{array}{l}\text { Interested in family history research. Top } 5 \text { corrector. } 1.2+\mathrm{m} \text { lines of } \\
\text { text correction, } 840 \text { comments (Feb 2014). Joined in August } 2008 .\end{array}$ \\
\hline 2 & $40-50$ & $\begin{array}{l}\text { Stay at home } \\
\text { mother }\end{array}$ & $\begin{array}{l}\text { Interested in family/local history and murders. Top } 10 \text { corrector. } \\
\text { Volunteers at Bendigo Historical Society } 1 \text { day per week. Joined in } \\
\text { August } 2008 .\end{array}$ \\
\hline 3 & $60-70$ & $\begin{array}{l}\text { Retired. Used to } \\
\text { own a small } \\
\text { business in IT }\end{array}$ & $\begin{array}{l}\text { Mostly interested in family research. Top } 5 \text { corrector. Corrected 2.3+ } \\
\mathrm{m} \text { lines of text correction, } 7 \text { comments. Joined in June } 2009 .\end{array}$ \\
\hline 4 & $50-60$ & $\begin{array}{l}\text { Retired. } \\
\text { Systems analyst } \\
\text { programmer }\end{array}$ & $\begin{array}{l}\text { Interested in family history. Top } 5 \text { corrector. Full-time volunteer. } \\
1.7+\mathrm{m} \text { lines of text correction, } 460 \text { comments. Joined in July } 2009 .\end{array}$ \\
\hline 5 & $50-60$ & $\begin{array}{l}\text { Retired. } \\
\text { Worked in } \\
\text { banking }\end{array}$ & $\begin{array}{l}\text { Interested in Family/local history and shipping. Top } 5 \text { corrector. } \\
\text { Married to Mr Hoy, shares the same Trove account. 1.1+m lines of } \\
\text { text correction, } 36 \text { comments (Feb 2014). Joined in August } 2008 .\end{array}$ \\
\hline 6 & $60-70$ & $\begin{array}{l}\text { Retired } \\
\text { worked in } \\
\text { Banking }\end{array}$ & $\begin{array}{l}\text { Interested in book chapters in newspaper, shipping. Top } 5 \\
\text { corrector. Married to Mrs Hoy, shares the same Trove account. } \\
1.1+\mathrm{m} \text { lines of text correction, } 36 \text { comments. Joined in August } 2008 \text {. }\end{array}$ \\
\hline 7 & $70+$ & $\begin{array}{l}\text { Retired, Author } \\
\text { and historian }\end{array}$ & $\begin{array}{l}\text { Interested in various things, related to her work. Top } 100 \text { corrector. } \\
\text { Active Trove forum volunteer. }\end{array}$ \\
\hline 8 & $60-70$ & $\begin{array}{l}\text { Manager of } \\
\text { Professional } \\
\text { Standards and } \\
\text { student } \\
\text { protection }\end{array}$ & $\begin{array}{l}\text { Interested in light railways. Active member of Light Railway } \\
\text { Research Association (LRRSA) and editor of their magazine. Only } \\
\text { tags relevant articles with LRRSA. }\end{array}$ \\
\hline 9 & $30-40$ & $\begin{array}{l}\text { Works part- } \\
\text { time. PhD } \\
\text { Student }\end{array}$ & $\begin{array}{l}\text { Interested in weather tables. He is the communications and project } \\
\text { officer for the Climate research group in University of Melbourne's } \\
\text { ARC linkage grant with NLA. The project collects weather tables } \\
\text { from Trove newspapers. Also, through their citizen science project, } \\
\text { additional people get involved with Trove. }\end{array}$ \\
\hline
\end{tabular}

Table 2.Summary of volunteer demographics and text correction practices

This study followed a thematic data analysis technique on the basis of iteratively exploring themes from gathered data as proposed by Saldaña (2015). First-cut coding was carried out using an 'open-coding' approach to identify common themes (Saldana 2015). Second cut analysis delved into further relevant concepts from the existing literature (i.e., intrinsic and extrinsic motivations) to gain a better understanding and explanations and lastly further concepts inductively developed during the analysis from on-going research into relevant theories (i.e. internalised extrinsic motivations). Final analysis broken these motivations into initial and continued participation.

One author conducted the initial round of coding in the original languages of the transcribed data. As we were particularly interested in CS motivations, we paid special attention that the coding included information such as why the participants joined the project, why the participants continued contributing to the project, and why the participants withdrew from 
the project (if applicable). The other author went through the coding and verified the codes until reaching a consensus. Both authors then organised the initial codes into potential categories and added motivational dynamics for initial and continued participation. As Table 3 shows, sample excerpts from the data for the emergent themes are presented as examples of saturation.

\begin{tabular}{|c|}
\hline Text-corrector Motivation \\
\hline Intrinsic motivation (category) \\
\hline Personal (interest) oriented motivation (sub-category) \\
\hline $\begin{array}{l}\text { Theoretical concepts: Personal interest (e.g. research goals), trust, challenge, learning new knowledge, } \\
\text { competition, topic of interest (Australian history), addiction, obligation, supportive environment }\end{array}$ \\
\hline $\begin{array}{l}\text { Interview comment: "Consequently my reason for using the site is foremost for family history/genealogy } \\
\text { reasons, but I also find the site invaluable as an aid in my research undertakings". }\end{array}$ \\
\hline $\begin{array}{l}\text { Data from documentation review: "When a Library appears to give up some control over its content it embodies } \\
\text { in its public a great deal of trust. The trust is honoured and grows as users become actively involved with the } \\
\text { content and feel a sense of responsibility working for the institution/service/common good. }\end{array}$ \\
\hline $\begin{array}{l}\text { Data from Trove forum: My motives are far from altruistic. I'm addicted to tatting and the prospect of finding } \\
\text { new patterns interests me, especially when they're by an Australian author whose book sits on my shelf. I live } \\
\text { in the Los Angeles, California area }\end{array}$ \\
\hline Timeline: Initial participation \\
\hline Community-based motivation (sub-category) \\
\hline $\begin{array}{l}\text { Theoretical concepts: Altruism, collectivism (e.g. genealogy), Principalism (or action significance by external } \\
\text { values) }\end{array}$ \\
\hline $\begin{array}{l}\text { Interview comment: "The Rockhampton group actually arranged that as a meeting; as a chance to get together } \\
\text { and have a chat and have a coffee as well as correct the text". }\end{array}$ \\
\hline Timeline: Continued participation \\
\hline Enjoyment-based motivation (sub-category) \\
\hline Theoretical concepts: Enjoyable/Fun/pleasure/recreation, Simplicity, Task Autonomy, Pastime \\
\hline Interview comment: "Just the enjoyment is my motivation and gain". "If I'm not doing anything else, I do this". \\
\hline Timeline: Initial and continued participation \\
\hline Extrinsic motivation (category) \\
\hline Social motivation/mechanisms (Non-monetary rewards) (sub-category) \\
\hline $\begin{array}{l}\text { Theoretical concepts: Acknowledgement, attribution and reward, desire for recognition (ranking table and Hall } \\
\text { of fame), rewards (Australian Day awards), indirect feedback, advocacy }\end{array}$ \\
\hline $\begin{array}{l}\text { Interview comment: Wow, the National Library - not so much I could get invited too but the National Library } \\
\text { really cares about this and acknowledges it. I think that was a really good thing to do. }\end{array}$ \\
\hline $\begin{array}{l}\text { Data from documentation review: The library invited the top five text correctors to Canberra on Australia Day } \\
\text { in } 2010 \text { to meet ANDP staff in recognition of their contributions to the project. }\end{array}$ \\
\hline Timeline: Continued participation \\
\hline
\end{tabular}

Table 3. Sample excerpts from the data for the emergent themes and coding analysis

\section{Findings}

In this section, we present our case analysis with rich illustrative quotations from interviews supported by documentary data. To highlight motivation dynamics, we detail whether the motivations instigated initial participation or continued participation. 


\subsection{CS Volunteers' Motivation: From Initial to Continued Participation}

\section{Intrinsic motivations}

Intrinsic motivation emphasises inherent sources of satisfaction rather than the separable consequences of the act (e.g., acting just for fun) (Ryan and Deci 2000). Volunteers reported various intrinsic motivations when initially joined Trove.

\section{Personally (Self)-oriented motivations}

Self-interest (own-use value): The volunteers interviewed reported that their initial involvement originated mostly from their own personal interest or goals. This is similar to open-sourced based peer production systems where developers were also found to be motivated by personal interests (Bonabeau 2009; von Krogh et al. 2013). The majority were people interested in family history research or genealogy, but some volunteers were also interested in researching historical events such as famous crimes and public transport history. A senior Trove support officer explained:

Actually, if you break down the top 10 text correctors, it's probably only 50 per cent genealogists. The others are sort of what we call recreational researchers. There's one who's fascinated with the history of murders and goes through and looks for those. Generally - most of the top - the heavy text correctors or the enthusiasts have started at least as enthusiasts of something, but it's not necessarily family history if that makes sense.

Trove volunteers reported a range of short- and long-term goals for initial and continued participation. For example, one volunteer was an author and used the facility to research topics relevant to her ongoing needs as a writer, while another volunteer only corrected articles with references to his family history.

Addiction: Some volunteers reported that they were 'hooked in' and 'addicted' to text correction, hinting addiction being a motivator for continued participation. The contributions by the top 10 text correctors consistently reflected a workload similar to that of a full-time job (40-60 hours per week). The top corrector at the time of interview admitted when asked about her reasons for continuation: 'I suppose initially it was to fill in some of the family history gaps in my family and I can say it is very addictive once you get really involved'.

Learning: Volunteers appreciated that they could learn new things and gain insights from the collection as they worked ("You learn stuff all the time"), hence indicating that learning contributed to both initial and continued participation.

\section{Affective Motivations}

We observed two types of affective motivations observed: hedonic-based motivations (e.g., fun, pastime, and interesting) and task-based motivations (e.g., simplicity and autonomy).

Fun: Many volunteers participated in text correction because it was fun and enjoyable. For example, one volunteer believed that'[j]ust the enjoyment is my motivation and gain'. They reported that they enjoyed the task and the interactions through tagging, commenting, and forming, which keeps them motivated over time.

Pastime: Many of the high performing volunteers were in their 50s and some of them were transitioning to retirement or already retired. They used the site to pass time and to keep active. A volunteer who had long retired said, 'If I' $m$ not doing anything else, I do this'. Hence, pastime was found to be a motivator for both initial and continued participation. 
Passion for topic: People were generally interested in topics such as history, science, animals, or particular hobbies and this was identified as motivator for their short and long-term participation (Ridge 2013). Newspapers were regarded as historical artefacts that people can relate to and connect with on a personal level. As one volunteer explained, 'I think people just like history, especially the sort of history that's presented in newspapers. It's something that they're very familiar with; it's not threatening like getting a history book off the shelf'.

Simplicity: Text correction was an easy task that does not need training. Such simplicity in operation allowed an easy-start for volunteers to join Trove. Further, many volunteers had previous experience of managing large volumes of data either at work or through their involvement with other genealogy projects (e.g., Ryerson index andancestry.com). As one volunteer explained, 'just personally, for example, a lot of old documents I have transcribed for my own personal use'.

Task autonomy: Another important motivator was the high-level of autonomy in task selection, which was attractive proposition for initial participation. Volunteers were free to act according to self-articulated goals and principles. There were no restrictions on the time taken to complete a task. There were no strict guidelines on how to do text correction and multiple options were available for carrying out the task. Task autonomy thus offered the volunteers freedom when working on Trove. As one volunteer commented, 'I do whatever tickles my fancy on the day'. Another said, 'You're not told how to do it. You're not told what you should do and what you shouldn't do. Do it at your leisure'.

\section{Community-based motivations}

Community-based motivations are characterised by an individual's perception of the task being important, meaningful, valuable, or worthwhile for a community: 'a common core is the disposition to benefit others' (Benkler and Nissenbaum 2006, p.407). We observed four related themes from the case.

Altruism: Many volunteers saw text correction as an altruistic patriotic task that would help preserve Australian history and the National Library. Volunteers believed that they were helping to provide an accurate record of Australian history. The search facility was being improved through text correction and, in turn, having a wider impact on the Australian community. For example, a volunteer expressed that 'it's being part of something bigger than them, being able to contribute something that has lasting value; being able to make a difference, being able to improve things for other people'. Altruism thus motivates both initial and continued participation.

Kinship/Collectivism: Volunteers also reported that they corrected text to increase the welfare of specific groups to which they belonged (kinship/collectivism) which contributed to sustained participation over time. For example, some text correctors were also members of genealogy sites (e.g. RootsWeb) and others volunteered for local libraries and genealogy societies (e.g., Bendigo Historical Society). volunteers formed many interest groups within and outside the Trove platform. For example, one such group were a Rockhampton based group who focused their correction efforts on their local newspaper. Another group were the Light Railway Research Society whose members tagged relevant newspaper articles to assist light railway researchers. We also observed another form of community that had no formal group structure but consisted of a loose network of volunteers. This loose affiliation led to collaboration independent of the NLA, which resulted in a text correction guideline. The need 
for a guideline stemmed from ongoing user practices and operational level text correction issues that arose due to the absence of formal rules. The top contributors collaborated through emails and the Trove forum to create and disseminate their own guideline with little assistance from NLA.

Ownership: Registered users comprise around 85 percent of corrections on Trove (Hagon 2013). The high correlation between user registration and text correction indicated that volunteers felt they 'belonged' to the service, and that they had forged a long-term relationship with the Library and the collection (Ayres 2013). As the Trove support officer explained:

Well I think by allowing users to register and create a profile, we have given them the opportunity to take ownership of the work that they're doing ... and would view themselves as individual stakeholders in the project, not just as part of the project.

Non-profit cause: Volunteers were much more likely to help not-for-profit organisations than commercial companies because they did not want to feel that their work can be commercially exploited as they believe they are contributing to public good. Based on norms and values of volunteerism, Trove volunteers were empathetic to the not-for-profit heritage context of the library that motivated their initial contribution. As the project manager explained:

Some of the success factors why they would help us as opposed to anyone else, is because we are not-for-profit, we don't have as much money as we like, and they see us as a worthy cause. People are much more likely to help libraries and archives than they are a whole lot of other organisations. Libraries per se, people are much more likely to help the National Library, because they perceive us to be more trustworthy and more honest and more reliable.

\section{Internalised Extrinsic Motivations}

Internalised extrinsic motivations are by definition extrinsic but were internalised by volunteers., such motivations were perceived as self-regulating behaviour rather than externally imposed (Ryan and Deci 2000; von Krogh et al. 2013). We identified four types of such motivations based on the case.

Trust: NLA's experience indicated that the greater the level of freedom and trust given to volunteers resulted in more being contributed, greater feelings of loyalty, and higher level of accuracy. Rather than assuming everything would go wrong and spending valuable resources putting systems in place to control the potential for vandalism (e.g., moderation), NLA assumed that users would do their best and monitor and help each other (Holley 2009). This approach succeeded and led to positive trusting relationship. The project manager wrote in a related NLA report (Holley 2010):

When a Library appears to give up some control over its content it embodies in its public a great deal of trust. The trust is honoured and grows as users become actively involved with the content and feel a sense of responsibility working for the institution/service/common good.

Obligation/reciprocity: Volunteers felt a sense of gratitude to the library for providing the resource and in return felt morally obligated to assist the library in improving the searchability of the resource, as on volunteer said 'I felt an obligation to repay the assistance that I have received from the existence of the site. To sing for my supper, so to speak'.

Challenge: For some volunteers, the more content provided, the more they felt motivated to contribute. Large amounts of new content were added as the program progressed which further motivated some volunteers to do more correction. 
Competition (internal self-concept): Two forms of competitive activity were observed within the case study. One common competitive activity involved volunteers setting their own productivity targets (e.g., how much text correction to be done per month) - an internal selfconcept motivation that drives individuals to pursue an activity that meets their inherent standards (Yang and Lai 2010). In this instance, the volunteers were interested to being able to check what and how much material they had corrected over time (monthly, weekly, etc.). These personal goals and aspirations increased their self-esteem.

However, evidence of rivalry among the top volunteers were evidenced over time as they competed to hold onto or improve their position on the ranking tables. This competitive attitude was observed between two top performers.

\section{Extrinsic Motivations}

In our case, volunteers were mostly intrinsically motivated, and the library offered no monetary incentives for carrying out text correction. Instead, the library deployed nonmonetary incentive mechanisms. Essentially two types of extrinsic motivators were found through data analysis: (1) reputation-based rewards and (2) social mechanisms. The social (or status) motivations implemented by the library thus had a 'crowding in' effect (Frey and Jegen 2001) over time as illustrated in the examples below.

\section{Reputation-based rewards}

Initially, the NLA did not offer acknowledgement or reward to volunteers, but later instigated a number of simple and cost-free rewards and acknowledgements as suggested by the volunteers. Acknowledgement of their achievements was important to the volunteer community. Such acknowledgement took many forms: attribution was done by identifying text correctors (or their account handles) on the articles they amended. Volunteers could immediately see what they had corrected. Importantly, it was possible for others to retrieve a newspaper article and see the list of people who contributed to the corrections in that article. It was also possible to search by a 'user profile' (or account handle) and see what corrections that person had done, their rankings, comments, and tags. The acknowledgements, attributions, and rewards recognised volunteers' contribution and became a key motivator for continued contribution.

Recognition via leader boards (e.g., ranking tables and the Hall of Fame) were extrinsically rewarding to volunteers. Leader boards were one of the few ways to obtain positive feedback for their effort, which enabled volunteers to track their progress and monitor others over time. Originally, the ranking table only showed the top 10 correctors. Gradually, due to requests from other volunteers, a Text Correctors Hall of Fame was added listing anyone who had corrected more than 1,500 lines of corrections in a month, as well as including a user's overall ranking on their user profile. These features added some competitiveness and continuity to motivate future contributions. Several staff and volunteers also mentioned other forms of recognition during interviews. For example, the library invited the top five text correctors to Canberra on Australia Day 2010 to meet ANDP staff as acknowledgement of their contributions to the project. The Lead IT Architect, Kent, reflected:

That was a fantastic idea. It got a lot of news in the media and made those people feel good and other text correctors think: Wow, the National Library - really cares about this and acknowledges it. 


\section{Social Mechanisms}

Indirect Feedback: Feedback mechanisms were initially expected to create an open communication channel between the NLA and volunteers, but these mechanisms also became prominent motivational factors. Indirect feedback motivated volunteers by increasing trust and self-competition. Indirect feedback took many forms within Australian newspapers site, such as impromptu updates about the newspaper correction and its progress on the actual website, regular email acknowledgement outstanding text correction work in general, and public postings on the forum and in NLA newsletters by the project team recognising the efforts of the text corrector volunteers. The project manager and senior NLA staff also recognised the work of the volunteers in conferences and other publications and through this, a lot of interest both nationally and internationally was generated among other libraries and in the media. Text corrector profiles were highlighted in invited seminars and workshops around the country. The publicity peaked when the text correction activity became reported by popular media, and many personal stories of text correction work were lauded in local newspapers. Thus, feedback motivated both initial and continued participation.

Advocacy: Advocacy can be seen as a collectivist motivation (unlike education, which emphasises the personal gains volunteers may receive from their participation in CS projects) that unfolded during continued participation. There was evidence of this form of motivation at work within the ADNP but to a lesser extent than reported in citizen science CS projects (see Rotman et al. 2012). Some volunteers saw the newly found knowledge (e.g., family history resource) as an educational benefit from which they not only gained personally, but also a knowledge base that they could later bring to their local and distributed communities and social networks.

\section{Summary}

Drawing from the case analysis, we propose a motivation typology for the not-for-profit CS settings as presented in Table 4. The typology has three high level categories: (1) intrinsic motivation, (2) internalised extrinsic motivation, and (3) extrinsic motivation. Intrinsic motivation includes the personally (self)-oriented motivations mostly driven by self-interest (or own-use value) and affective motivations that are related to task characteristics and enjoyment, as well as community-based motivations that identify with the welfare and principles of the group or collective. The extrinsic motivations include non-monetary social mechanisms and reputation-based motivations. The data also shows internalized extrinsic motivations that are extrinsic in nature but perceived as intrinsic due to their self-regulatory nature.

The proposed motivation typology extends previous studies in the not-for-profit CS contexts (cf. Table 1 and Table 4). For example, volunteers are dominantly motivated by personalintrinsic motivations, particularly in this case for their interests in family history research and genealogy. Indirect feedback and reputation-based rewards were also found to be useful. Two motivators were found to be prominent in contrast to previous studies: passion for topic and non-profit cause. Passion for historical artefacts such as old newspapers were found to play an important role in engaging volunteers. Additionally, not-for-profit cause was found to be a major player in their decision to continue to correct text, as it was a national resource. These two motivators were unique to the GLAM CS contexts. 


\begin{tabular}{|l|l|l|l|}
\hline \multicolumn{2}{|c|}{ Motivation Type } & \multicolumn{1}{c|}{ Category } & \multicolumn{1}{c|}{ Constructs } \\
\hline $\begin{array}{l}\text { Intrinsic } \\
\text { motivations }\end{array}$ & Personal & $\begin{array}{l}\text { Personally (self)- } \\
\text { oriented motivation }\end{array}$ & Own-use (self-interest), Learning, Addiction \\
\cline { 2 - 4 } & Affective motivation & $\begin{array}{l}\text { Fun, Pastime, Passion for Topic, Simplicity, Task } \\
\text { Autonomy }\end{array}$ \\
\cline { 2 - 4 } & Social & $\begin{array}{l}\text { Community-based } \\
\text { motivation }\end{array}$ & $\begin{array}{l}\text { Altruism, Kinship/Collectivism) Non-profit cause, } \\
\text { Ownership }\end{array}$ \\
\hline $\begin{array}{l}\text { Internalised } \\
\text { Extrinsic } \\
\text { motivations }\end{array}$ & Personal & Self-esteem & Challenge, Competition (internal self-concept), \\
\cline { 2 - 4 } & Social & Pro-social motivation & Trust, Obligation \\
\hline $\begin{array}{l}\text { Extrinsic } \\
\text { motivations }\end{array}$ & Personal & Reputation-based & Recognition \& reputation-based reward, Attribution \\
\cline { 2 - 4 } & Social & Social Mechanisms & Indirect feedback, Advocacy \\
\hline
\end{tabular}

Table 4. Motivation typology of motivation of voluntary CS

\subsection{Motivational Dynamics from Beginner to Leading Contributions}

In addition to previous analysis, to further explore motivational dynamics, we observed how the motivations and work practices of contributors changed over time from initial to sustained participation as they moved from being a novice volunteer to high-performing volunteer (ranked top 1000 in the Hall of Fame).

High-performing volunteers reported they were initially motivated by self-serving research interests (e.g., genealogy, Australian history, and famous crimes). For example, many volunteers first encountered the digitised resource while researching a specific topic. While others were referred to the site from genealogy forums and blogs:

I was alerted to the site through an email posted on a Jewish email site that I subscribe to. I straight away began to look for any family notices that I could add to my family tree, and I think one of the first articles I corrected was the death notice of my great great grandfather in 1922. I have been interested in family history for about 35 years, and the newspaper site was just another avenue to explore to garner more details.

Volunteers described the transition from initial involvement to active involvement as broadening of focus from their initial research interest to other sometimes much wider areas of interest:

My personal interests are in family history, but I don't confine myself to correcting articles or family notices, as we call them. I often go off on tangents and I have corrected many things.

Text correction also becomes a routine task in conjunction with other daily chores:

Any correction done during the day may be done on and off through normal household interruptions.

In the move from active volunteer to high-performing, motivations broadened to include altruistic goals of improving a public good that is of historical significance to Australians, and collective goals of servicing specific needs of special interest groups (e.g. genealogy societies, railway researchers). The project manager of ANDP reflected: "The sense of making history, being a part of history and recording history is very important to most Australians. So Australian genealogists are perhaps even more community spirited than other nations and perhaps this is why the text correction 
has been so successful." A top text corrector who was a genealogist confirmed, "I also voluntarily help a lot of people with their family history research".

Further, volunteers reported a greater awareness of advanced features of the CS platform as they become more active on the site. Individuals could establish an identity profile within the site through their user account, which allowed them to track their own contributions (e.g., text corrections, tags, and comments), progress and comparative ranking against others (e.g., monthly leader boards and the Hall of Fame). They used the additional features of tagging and commenting as necessary to support their work as one volunteer explained:

I tag most of my work, where it seems appropriate, and when considering a new tag, I check to see how any existing tag on the topic is entered. I enter comments only rarely, usually when there is some serious fault either in the original article, or in the computerisation, and occasionally if there is a gross factual error.

Regular contributors also assumed that others would adopt the role of moderator:

I am able to ask when I feel I need help. If I am accidentally doing the wrong thing, I hope that somebody will notice and tell me. If they do not, well, at least the text will be better when I have finished working on it than it was when I started.

As volunteers moved from occasional contribution to frequent and routine text correction, some assumed additional administrative and leadership roles. Their scope of activities extended beyond mere serendipitous editing. For example, leading contributors also assumed the role of moderation and maintained a strong sense of preserving standards. They used user profiles to monitor and track accuracy and quality of correction as if it was their responsibility to maintain the integrity of the corrected articles. They actively voiced their concerns over incorrect editing (e.g. how to correct em-dashes). For example:

It upsets me to see someone changing data which is fixed historically and not correcting it properly. I found, in the last week, another user has been doing corrections and using ampersands, changing line breaks, capitalising words, adding his own words to births, deaths and marriages. I've done the corrections that he's been doing and I'm recorrecting them.

A small number of leading correctors reported that they felt compelled to take further responsibility as their tenure of involvement extended beyond one or two years. Two of the leading correctors interviewed had volunteered to draft text correction and tagging guidelines for the library. They also offered words of advice through participation in the Trove forum and through invited presentations:

If people want help, the couple of particular librarians involved in local studies and family history have my name and contact number and so they will give people my phone number if they need assistance and take it from there.

\subsection{Typology of Dynamic Changes in Motivation over Time}

We have shown insights into how leading contributors began their journey and over time became heavily active. Specifically, their participation transformed from novices to leading contributors. As their participation become routine and frequent, volunteers reported that they adopted new goals and leadership roles even though there was no formal role structure within the site. Over time, their motivations changed and broadened as the extrinsic motivations were introduced through reputation-based mechanisms (e.g., recognition and attribution). 
High-performing volunteers reported high intrinsic motivation but lower extrinsic motivation at the initial stage. Most text correctors presented a range of personal and community-centric motivations as the most substantial motivation for their initial engagement. External motivations such as recognition and rewards played a secondary role, but these factors had a greater impact on long-term engagement in the project (see Table 5). For example, when text correctors reassessed their ongoing participation in text correction, both intrinsic and extrinsic motivations combined to play a vital role in their decision to continue to support the ANDP. Establishing the "right balance" between intrinsic and extrinsic motivations of top text correctors facilitated their sustained participation over time. For non-profit GLAM context, internalised extrinsic motivators (e.g. trust and reciprocity) can play a vital role.

\begin{tabular}{|l|l|l|l|}
\hline \multicolumn{1}{|c|}{ Motivation } & \multicolumn{1}{|c|}{ Category } & \multicolumn{1}{c|}{ Initial Participation } & \multicolumn{1}{c|}{ Continued Participation } \\
\hline \multirow{5}{*}{$\begin{array}{l}\text { Intrinsic } \\
\text { motivations }\end{array}$} & $\begin{array}{l}\text { Personally (self)- } \\
\text { oriented motivation }\end{array}$ & $\begin{array}{l}\text { Own-use (self-interest), topic of } \\
\text { interest }\end{array}$ & Learning, Addiction \\
\cline { 2 - 4 } & $\begin{array}{l}\text { Affective } \\
\text { motivation }\end{array}$ & $\begin{array}{l}\text { Fun, Pastime, Passion for Topic, } \\
\text { Simplicity, Task Autonomy }\end{array}$ & $\begin{array}{l}\text { Fun, Pastime, Passion for Topic, } \\
\text { Task Autonomy }\end{array}$ \\
\cline { 2 - 4 } & $\begin{array}{l}\text { Community-based } \\
\text { motivation }\end{array}$ & Altruism, Non-profit cause & $\begin{array}{l}\text { Altruism, Kinship } \\
\text { (Collectivism), Ownership }\end{array}$ \\
\hline \multirow{2}{*}{$\begin{array}{l}\text { Internalised } \\
\text { motrinsic }\end{array}$} & Self-esteem & Challenge & $\begin{array}{l}\text { Challenge, Competition } \\
\text { (internal self-concept) }\end{array}$ \\
\cline { 2 - 5 } & $\begin{array}{l}\text { Pro-social } \\
\text { motivation }\end{array}$ & Trust & Obligation/reciprocity \\
\hline motivations & Reputation-based & Attribution & $\begin{array}{l}\text { Recognition \& Reputation-based } \\
\text { reward }\end{array}$ \\
\cline { 2 - 4 } & Social Mechanisms & Indirect feedback & Advocacy \\
\hline
\end{tabular}

Table 5. A typology of motivational dynamics for voluntary CS

\section{Discussion and Conclusion}

In this section, we first summarised the key contributions of our study, followed by their implications for researchers and practitioners. We then illustrate limitations of this study and propose opportunities for further research.

\subsection{Contributions}

The paper makes two principal contributions. First, drawing on the Trove case, the paper offers a comprehensive understanding of the changing nature of volunteer motivation in a not-for-profit CS context. The majority of the volunteers presented a range of personal (i.e., personal interest, and fun) and community-centric motivations (i.e., altruism and non-profit cause) as the most substantial motivation for their initial engagement. External motivations (i.e., recognition and rewards) played a secondary role but had a greater impact on long-term engagement in the project. Thus, we contribute to the understudied debate on volunteer motivation changes for different stages of contributions and respond to the call for research on motives for contribution to consider both the stage of participation and separate motives for those stages for contribution (Crowston and Fagnot 2018). Second, the empirically grounded theorisation of the typology and detailed motivational, technical, and relational aspects of motivation have implications for how to design and configure volunteer interactions and incentive designs over time to be successful. 


\subsection{Implications for Research}

The main contribution from this study was the temporality in the proposed volunteer motivation typology for not-for-profit CS projects. The case provided insights into the work practices, tool use, and management strategies behind volunteer engagement and transition from initial involvement to ongoing active contribution. We responded to the call by Crowston and Fagnot (2018) to consider different stage of participation and to separate motives for different stages of participation and contribution. The study found that a complex framework of personal, collective, and external factors motivated the volunteers. Volunteers were highly intrinsically motivated, but community and external factors including non-monetary rewards played a vital role in their continued involvement. Volunteers largely began participating because they were interested in a particular subject area and had some use for the material that they found (e.g., their own family history), and they found correcting to be fun. They could also justify the time spent because they felt that they were contributing to social good. Some CS support mechanisms were principally useful in encouraging the leading volunteers by acknowledging their valuable work. The study also found that volunteer's motivations were varied and often temporal, which suggests that motive alignment is also dynamic and may require adjustment over time to encourage ongoing participation. As we come to better understand the changing motivations of this new breed of digital volunteers of cultural data, we can better incorporate these motivations into the design of future not-for-profit CS collaboration sites.

\subsection{Implications for Practice}

The volunteer motivations and dynamics have implications for future design and practice in the following areas (see Table 6).

\begin{tabular}{|l|l|l|l|}
\hline \multicolumn{1}{|c|}{ Design implications } & \multicolumn{1}{|c|}{ Motivation } & \multicolumn{1}{|c|}{ Involvement } & \multicolumn{1}{c|}{ Design mechanics } \\
\hline $\begin{array}{l}\text { Design appropriate } \\
\text { incentive mechanisms }\end{array}$ & $\begin{array}{l}\text { Extrinsic } \\
\text { motivation }\end{array}$ & $\begin{array}{l}\text { Both initial and sustained } \\
\text { involvement }\end{array}$ & $\begin{array}{l}\text { Design non-monetary reputation- } \\
\text { based incentive mechanisms (e.g. } \\
\text { leader boards, user profiles) }\end{array}$ \\
\hline $\begin{array}{l}\text { Design appropriate } \\
\text { organisational } \\
\text { relational mechanisms }\end{array}$ & $\begin{array}{l}\text { Both intrinsic } \\
\text { and extrinsic } \\
\text { motivation }\end{array}$ & $\begin{array}{l}\text { Both initial and sustained } \\
\text { involvement }\end{array}$ & $\begin{array}{l}\text { Design for open communication } \\
\text { and treat users as partners (e.g. } \\
\text { forum, contact us form) }\end{array}$ \\
\hline $\begin{array}{l}\text { Design to build } \\
\text { community }\end{array}$ & $\begin{array}{l}\text { Intrinsic } \\
\text { motivation }\end{array}$ & Sustained involvement & $\begin{array}{l}\text { Design to support smaller } \\
\text { communities within the larger } \\
\text { crowdsourcing site (i.e. sub- } \\
\text { groups) with common interest } \\
\text { (e.g. forum/forum threads) }\end{array}$ \\
\hline $\begin{array}{l}\text { Design to support } \\
\text { different forms of } \\
\text { contributions }\end{array}$ & Intrinsic & $\begin{array}{l}\text { initial and sustained } \\
\text { involvement } \\
\text { Design features like tagging, } \\
\text { commenting, lists, merge and } \\
\text { splits to allow submission of } \\
\text { multiple forms of contributions }\end{array}$ \\
\hline $\begin{array}{l}\text { Design for social } \\
\text { support }\end{array}$ & Extrinsic & $\begin{array}{l}\text { initial and sustained } \\
\text { participation }\end{array}$ & $\begin{array}{l}\text { Design should incorporate new } \\
\text { social networking tools (e.g. } \\
\text { Facebook, Twitter, blog) }\end{array}$ \\
\hline
\end{tabular}

Table 6. Practice and design implications of volunteer motivation

Design appropriate incentive mechanisms

The findings from this study demonstrate emphatically the importance of considering appropriate motivation elements in CS platform design. CS platforms and support systems 
should align with volunteer motivations in order to attract, incentivise, sustain, and guide the crowd to complete required tasks. Although the NLA was initially unable or unwilling to offer acknowledgement or rewards to volunteers (e.g. during the design stage), they later instigated a number of simple and cost-free rewards and acknowledgements (e.g., Hall of fame, user profiles, website acknowledgement, and leader boards) which became effective extrinsic motivators for active and sustained participation.

\section{Design appropriate organisational relational mechanisms}

The NLA engaged volunteers through both formal and informal channels of communication and progressively gained a better understanding of their motivations and requirements. Organisational relational mechanisms (e.g., beta launch, community moderation, and feedback) were also used to reinforce intrinsic and extrinsic motivations. Through iterative and progressive version releases, the NLA incorporated design elements suggested by volunteers thus creating motivational affordances that aligned volunteer motivations with that of the Trove CS project. While moderation and punitive measures can reduce malicious behaviour, they can also have negative effects on participation. Hence, the NLA chose to put its trust in volunteers and community moderation by making the platform more accessible and not requiring registration.

\section{Design to build a community}

Wikipedians view their participation on the site as membership in a community where volunteers may adopt new goals and roles, and use different tools such as email, forum (Bryant et al. 2005). In the Trove case, a sense of community was present through participation in the online forum. There was also evidence of smaller groups forming informally within the site (e.g. LRRSA, climate change group, and Rockhampton Trovers). Although the forum supported creation of sub-groups for respective purposes, these groups were rather loosely coupled. Hence, it is useful to facilitate the formation of sub-groups within the wider volunteer cohort supported by appropriate social mechanisms (e.g., promotion of sub-groups) and design features (e.g. ability to send invitation to join sub-groups, a list of active sub-groups).

\section{Designing to support different forms of contributions}

Yates et al. (2010) and Majchrzak and Malhotra (2013) in their recent work on virtual CoPs and organisational wiki distinguish between personal knowledge contribution (i.e., adding content to wiki) and knowledge shaping (i.e., rewriting, integrating and restructuring wiki content). They use the term 'shaping' as an activity that changes a knowledge asset without adding domain knowledge. In a similar disposition, GLAM CS volunteers contributed to not only text correction, but also contributed additional shaping data regarding the digitised newspaper through features such as tagging and commenting. The library provided a forum to facilitate further meaningful conversations around the newspaper data that motivated volunteer engagement. Hence while designing CS technology for volunteerism, the designed features should enable and support not just the CS task (e.g., text correction/text transcription/text translation), but also knowledge shaping activities with design features such as tagging, commenting, forums, and lists (Zheng et al. 2011). Different forms of contributions can be promoted by highlighting the uses of tags, comments and lists on the CS platform along with statistics (see Figure 5 on how the library advertises the knowledge shaping activities on its home page). The forum can again provide further illustrations of how different forms of contributions are being sought within the CS system. 
Design for social support

CS platforms can provide extended ways of communicating and connecting with the CS service through social networking sites for volunteer engagement and awareness. For example, the Trove team decided in 2011 to include a blog (within the Trove forum) and Twitter account (https://twitter.com/TroveAustralia) to promote their collections. The blog was a way to display their collections to the public and to assist with finding new things. Links to these social networking sites were visible from the Trove home page.

\subsection{Research Limitations and Future research}

The study is exploratory in several respects and has other limitations that warrant comment. First, the research was conducted as a qualitative interpretive single case study. Despite the richness and comprehensives, generalisability has long been a shortcoming for single case studies. Thus, we encourage future studies to further examine and generalise our findings. For example, Gerber and Hui (2013) investigated the motivations for both creators and supporters of crowdfunding. Future studies should be conducted of CS work in more diverse settings in order to further enrich understanding about volunteer motivation in CS projects (e.g. for-profit company sponsored CS projects, cross-project variables and impacts). In addition, the nationality of volunteers may yield different results (e.g., Kobayashi et al. 2015). Empirical studies from a greater variety of cultural settings may serve to further explore, validate or highlight new issues and complexities.

Having distinguished the variances in motives in different stages of CS participation, future research should examine empirically how volunteers move from one stage to the other (Crowston and Fagnot 2018). Based on our findings, we saw that novice contributors are motivated to move to sustained participation through active involvement with the project. Future research should examine relational, technical, and organisational factors that explain the dynamics described above (e.g., Arazy et al. (2017) examines roles in Wikipedia).

Another significant stream of potential research is the conduct of longitudinal studies to investigate dynamic changes in motivation for collaborative GLAM CS initiatives to understand better the antecedents of participation and subsequent behavioural influences on sustained involvement. While several important motivational factors have been identified in this study, additional research is required to assess their interdependence, as not all constructs may be monocausal.

Participation in online communities tends to manifest as a long-tail distribution. That is, a comparatively small, active minority produce most of the content while the majority of community members produce very little (Budhathoki and Haythornthwaite 2013; Halfaker et al. 2013). A similar usage and text correction pattern were observed in the ANDP project (cf. Ayres 2013, Hagon 2013). However, studies of contributors to Wikipedia and similar online platforms (e.g., Amazon Mechanical Turk) show that top performers behave markedly different to others (Halfaker et al. 2013). This study did not investigate all possible forms of participation, but instead concentrated on the leading volunteer group who carried out the majority the text enhancements. Future research should consider the motivations of lessproductive contributors in the GLAM CS context.

The relationship between intrinsic and extrinsic motivation at depth and 'crowding-out' effects on intrinsic motivations requires further detailed examination (Frey and Jegen 2001). Also needed is an understanding of how different combinations of intrinsic and extrinsic 
motivations can best work with different problem types (e.g., contest vs. problem solving), and how these motivators affect composition of the crowd (Pedersen et al. 2013).

\section{Vale John Campbell}

John Campbell was a Professor of Business Information Systems at the Australian National University. A major theme throughout his research work is how users interact through information systems in the social world and, in particular, the ways in which organizational decision-making and community interaction are enacted through collaborative technologies. John engaged in a wide range of research topics including IT governance and business alignment, user security practices, evaluating IT investments, technology and work nexus, and virtual organizations, communities and teams. Unfortunately, John passed away on 14th January 2019. John was the first author's PhD supervisor and the second author's academic mentor. This paper extends the first author's thesis work. We would like to take this opportunity to acknowledge John's contribution to the national and international information systems community.

\section{References}

Adams, C., and Ramos, I. 2010. "The Past, Present and Future of Social Networking and Outsourcing: Impact on Theory and Practice," UK Academy for Information Systems Conference Proceedings 2010: Information Systems: past, present and looking to the future.

Afuah, A., and Tucci, C. L. 2012. "Crowdsourcing as a Solution to Distant Search," Academy of Management Review (37:3), pp. 355-375.

Alam, S. L., and Campbell, J. 2017. "Temporal Motivations of Volunteers to Participate in Cultural Crowdsourcing Work," Information Systems Research (28:4), pp. 744-759.

Arazy, O., Liifshitz-Assaf, H., Nov, O., Daxenberger, J., Balestra, M., and Cheshire, C. 2017. "On the How and Why of Emergent Role Behaviors in Wikipedia," Proceedings of the 2017 ACM Conference on Computer Supported Cooperative Work and Social Computing: ACM, pp. 2039-2051.

Ayres, M ( 2013). Singing for their supper: Trove, Australian newspapers, and the crowd. Paper presented at the IFLA WLIC 2013, Singapore, 1-9

Benkler, Y., and Nissenbaum, H. 2006. "Commons-Based Peer Production and Virtue," Journal of political philosophy (14:4), pp. 394-419.

Brabham, D. C. 2010. "Moving the Crowd at Threadless: Motivations for Participation in a Crowdsourcing Application," Information, Communication \& Society (13:8), pp. 1122-1145.

Brabham, D. C. 2012. "Motivations for Participation in a Crowdsourcing Application to Improve Public Engagement in Transit Planning," Journal of Applied Communication Research (40:3), pp. 307-328.

Budhathoki, N. R., and Haythornthwaite, C. 2013. "Motivation for Open Collaboration: Crowd and Community Models and the Case of Openstreetmap," American Behavioral Scientist (57:5), pp. 548-575.

Chandler, A. D. 1962. "Strategy and Structure: Chapters in the History of American Industrial Enterprises," Cambridge. hlass.: MIT Press (14), p. 16. 
Cobb, C., McCarthy, T., Perkins, A., Bharadwaj, A., Comis, J., Do, B., and Starbird, K. 2014. "Designing for the Deluge: Understanding \& Supporting the Distributed, Collaborative Work of Crisis Volunteers," Proceedings of the 17th ACM conference on Computer supported cooperative work \& social computing: ACM, pp. 888-899.

Crowston, K., and Fagnot, I. 2018. "Stages of Motivation for Contributing User-Generated Content: A Theory and Empirical Test," International Journal of Human-Computer Studies (109), pp. 89-101.

Deci, E. L. 1971. “Effects of Externally Mediated Rewards on Intrinsic Motivation," Journal of Personality and Social Psychology (18:1), pp. 105-115.

Deci, E. L., Connell, J. P., and Ryan, R. M. 1989. “Self-Determination in a Work Organization," Journal of Applied Psychology (74:4), pp. 580-590.

Deng, X., Joshi, K., and Galliers, R. D. 2016. "The Duality of Empowerment and Marginalization in Microtask Crowdsourcing: Giving Voice to the Less Powerful through Value Sensitive Design," MIS Quarterly (40:2), pp. 279-302.

Doan, A., Ramakrishnan, R., and Halevy, A. Y. 2011. "Crowdsourcing Systems on the WorldWide Web," Communications of the ACM (54:4), pp. 86-96.

Dutton, W. H. 2010. "Networking Distributed Public Expertise: Strategies for Citizen Sourcing Advice to Government," One of a Series of Occasional Papers in Science and Technology Policy, Science and Technology Policy Institute, Institute for Defense Analyses, Pennsylvania Avenue, Washington DC).

Eisenhardt, K. M. 1989. "Building Theories from Case Study Research," Academy of Management review (14:4), pp. 532-550.

Frey, B. S., and Jegen, R. 2001. "Motivation Crowding Theory," Journal of Economic Surveys (15:5), pp. 589-611.

Gagné, M., and Deci, D. 2005. “Self-Determination Theory and Work Motivation," Journal of Organizational Behavior (26:4), pp. 331-362.

Gerber, E. M., and Hui, J. 2013. "Crowdfunding: Motivations and Deterrents for Participation," ACM Transactions on Computer-Human Interaction (TOCHI) (20:6), p. 34.

Grewal-Carr, V., and Bates, C. 2016. "The Three Billion: Enterprise Crowdsourcing and the Growing Fragmentation of Work," Deloitte, retrieved from https://www2.deloitte.com/content/dam/Deloitte/de/Documents/Innovation/us-consenterprise-crowdsourcing-and-growing-fragmentation-of-work (20:3).

Hagon, P. 2013. "Trove Crowdsourcing Behaviour." Retrieved 21 November 2019, from https://www.nla.gov.au/our-publications/staff-papers/trove-crowdsourcing-behaviour

Halfaker, A., Keyes, O., and Taraborelli, D. 2013. "Making Peripheral Participation Legitimate: Reader Engagement Experiments in Wikipedia," Proceedings of the 2013 conference on Computer supported cooperative work: ACM, pp. 849-860.

Holley, R. 2009. Many Hands Make Light Work: Public Collaborative OCR Text Correction in Australian Historic Newspapers. National Library of Australia.

Holley, R. 2010. "Crowdsourcing: How and Why Should Libraries Do It?," D-Lib magazine (16:3/4 Ma). 
Howe, J. 2006. "The Rise of Crowdsourcing," Wired magazine (14:6), pp. 1-4.

Karen, S.-Y., and Cyndi, S. 2011. "Social Metadata for Libraries, Archives and Museums Part 1: Site Reviews." Retrieved 21 November, 2019, from http://www.oclc.org/research/publications/library/2011/2011-02.pdf

Kaufmann, N., Schulze, T., and Veit, D. 2011. "More Than Fun and Money. Worker Motivation in Crowdsourcing-a Study on Mechanical Turk," AMCIS: Detroit, Michigan, USA, pp. 111.

Klein, H. K., and Myers, M. D. 1999. "A Set of Principles for Conducting and Evaluating Interpretive Field Studies in Information Systems," MIS Quarterly (23:1), pp. 67-94.

Kobayashi, M., Arita, S., Itoko, T., Saito, S., and Takagi, H. 2015. "Motivating MultiGenerational Crowd Workers in Social-Purpose Work," Proceedings of the 18th ACM Conference on Computer Supported Cooperative Work \& Social Computing: ACM, pp. 18131824.

Lincoln, Y. S., and Guba, E. G. 1985. "Naturalistic Inquiry," The Blackwell Encyclopedia of Sociology).

Majchrzak, A., and Malhotra, A. 2013. "Towards an Information Systems Perspective and Research Agenda on Crowdsourcing for Innovation," The Journal of Strategic Information Systems (22:4), pp. 257-268.

Malone, T. W., Laubacher, R., and Dellarocas, C. 2010. "The Collective Intelligence Genome," MIT Sloan Management Review (51:3), p. 21.

McInnis, B. J., Murnane, E. L., Epstein, D., Cosley, D., and Leshed, G. 2016. "One and Done: Factors Affecting One-Time Contributors to Ad-Hoc Online Communities," Proceedings of the 19th ACM Conference on Computer-Supported Cooperative Work E Social Computing: ACM, pp. 609-623.

Nov, O. 2007. "What Motivates Wikipedians?," Communications of the ACM (50:11), pp. 60-64.

Oomen, J., and Aroyo, L. 2011. "Crowdsourcing in the Cultural Heritage Domain: Opportunities and Challenges," Proceedings of the 5th International Conference on Communities and Technologies: ACM, pp. 138-149.

Orlikowski, W. J., and Baroudi, J. J. 1991. "Studying Information Technology in Organizations: Research Approaches and Assumptions," Information Systems Research (2:1), pp. 1-28.

Owens, T. 2013. "Digital Cultural Heritage and the Crowd," Curator: The Museum Journal (56:1), pp. 121-130.

Pedersen, J., Kocsis, D., Tripathi, A., Tarrell, A., Weerakoon, A., Tahmasbi, N., Xiong, J., Deng, W., Oh, O., and De Vreede, G.-J. 2013. "Conceptual Foundations of Crowdsourcing: A Review of Is Research," 2013 46th Hawaii International Conference on System Sciences: IEEE, pp. 579-588.

Rafaeli, S., and Ariel, Y. 2008. "Online Motivational Factors: Incentives for Participation and Contribution in Wikipedia," Psychological aspects of cyberspace: Theory, research, applications (2:08), pp. 243-267.

Ridge, M. 2013. "From Tagging to Theorizing: Deepening Engagement with Cultural Heritage through Crowdsourcing," Curator: The Museum Journal (56:4), pp. 435-450. 
Rodell, J. B. 2013. "Finding Meaning through Volunteering: Why Do Employees Volunteer and What Does It Mean for Their Jobs?," Academy of Management Journal (56:5), pp. 1274-1294.

Rotman, D., Hammock, J., Preece, J. J., Boston, C. L., Hansen, D. L., Bowser, A., and He, Y. 2014. "Does Motivation in Citizen Science Change with Time and Culture?," Proceedings of the companion publication of the 17th ACM conference on Computer supported cooperative work E social computing: ACM, pp. 229-232.

Rotman, D., Preece, J., Hammock, J., Procita, K., Hansen, D., Parr, C., Lewis, D., and Jacobs, D. 2012. "Dynamic Changes in Motivation in Collaborative Citizen-Science Projects," Proceedings of the ACM 2012 Conference on Computer Supported Cooperative Work: ACM, pp. 217-226.

Ryan, R. M., and Deci, E. L. 2000. "Intrinsic and Extrinsic Motivations: Classic Definitions and New Directions," Contemporary Educational Psychology (25:1), pp. 54-67.

Saldaña, J. 2015. The Coding Manual for Qualitative Researchers. Sage.

Schlagwein, D., and Bjørn-Andersen, N. 2014. "Organizational Learning with Crowdsourcing: The Revelatory Case of Lego," Journal of the Association for Information Systems (15:11), pp. 754-778.

Starbird, K., and Palen, L. 2011. "Voluntweeters: Self-Organizing by Digital Volunteers in Times of Crisis," Proceedings of the SIGCHI conference on human factors in computing systems: ACM, pp. 1071-1080.

Taylor, J., and Joshi, K. D. 2019. "Joining the Crowd: The Career Anchors of Information Technology Workers Participating in Crowdsourcing," Information Systems Journal (29:3), pp. 641-673.

Turner, J. C., and Patrick, H. 2008. "How Does Motivation Develop and Why Does It Change? Reframing Motivation Research," Educational psychologist (43:3), pp. 119-131.

von Krogh, G., Haefliger, S., Spaeth, S., and Wallin, M. W. 2012. "Carrots and Rainbows: Motivation and Social Practice in Open Source Software Development," MIS Quarterly (36:2), pp. 649-676.

Yang, H.-L., and Lai, C.-Y. 2010. "Motivations of Wikipedia Content Contributors," Computers in human behavior (26:6), pp. 1377-1383.

Yates, D., Wagner, C., and Majchrzak, A. 2010. "Factors Affecting Shapers of Organizational Wikis," Journal of the American Society for Information Science and Technology (61:3), pp. 543554.

Zheng, H., Li, D., and Hou, W. 2011. "Task Design, Motivation, and Participation in Crowdsourcing Contests," International Journal of Electronic Commerce (15:4), pp. 57-88.

Copyright: $@ 2020$ Alam, Sun \& Campbell. This is an open-access article distributed under the terms of the Creative Commons Attribution-NonCommercial 3.0 Australia License, which permits non-commercial use, distribution, and reproduction in any medium, provided the original author and AJIS are credited. 


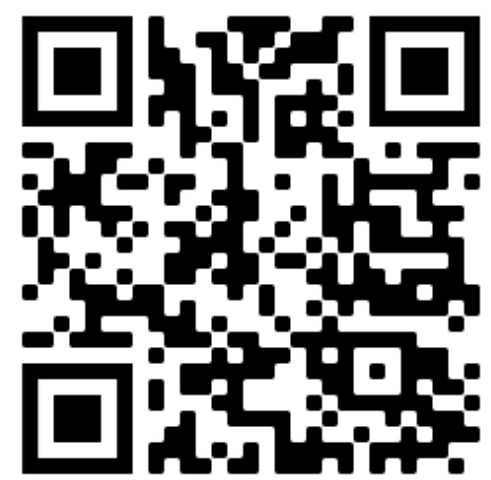

